\title{
PERTUNJUKAN SENI DI LOKASARI
}

\author{
Kaleb Yordan Santoso ${ }^{1)}$, Mieke Choandi ${ }^{2)}$ \\ 1)Program Studi S1 Arsitektur, Fakultas Teknik, Universitas Tarumanagara, bun_merdianto@outlook.com \\ ${ }^{2)}$ Program Studi S1 Arsitektur, Fakultas Teknik, Universitas Tarumanagara, miekec@ft.untar.ac.id
}

\begin{abstract}
Abstrak
Masyarakat kota merupakan masyarakat modern dengan banyak rutinitas dan aktivitas serta mobilitas yang tinggi. Keseharian ini menuntut mereka dengan gaya hidup serba cepat dan praktis. Gaya hidup seperti ini menuntut masyarakat kota untuk menghadapi suatu pekerjaan dan kegiatan yang begitu menyita waktu sehingga membuat mereka lupa akan kebutuhan lainnya (hiburan, waktu bersama keluarga) termasuk istirahat. Penelitian ini memiliki tujuan menjawab kebutuhan masyarakat, terutama masyarakat Kelurahan Tangki yang merupakan salah satu daerah pusat kota Jakarta melalui peran arsitektur dalam menciptakan ruang untuk beristirahat dan relaksasi di tengah kepadatan aktivitas yang dijalani (Third Place). Dalam penelitian ini, metode yang digunakan adalah melakukan studi, observasi dan penyebaran kuesioner sebagai pengumpulan data awal. Kedua, meneliti, mempelajari dan meninjau kebutuhan dari masyarakat sekitar serta kebutuhan untuk melepas kejenuhan dan beristirahat ditengah aktivitas yang banyak dan padat. Ketiga, menyusun program yang sesuai dengan hasil survei, observasi serta untuk menjawab kebutuhan masyarakat yang disesuaikan dengan soal agar terciptanya suatu Third Place yang berhasil sehingga tujuan proyek akan tercapai. Proyek third place Pertunjukan Seni ini menunjukkan dan memberikan sebuah wadah yang dibutuhkan bagi masyarakat khususnya di Kelurahan Tangki dengan mengembangkan dan membangkitkan program lama dari sebuah Lokasari, menjadi program campuran dari kebudayaan lama dengan kebudayaan zaman sekarang guna menarik semua umur dan gender.
\end{abstract}

\section{Kata kunci: kebutuhan; rutinitas; tangki; third place}

\begin{abstract}
Modern society with many routines and activities with high mobility. This everyday demands them with a fast and practical lifestyle. This lifestyle requires the city community to move to work and activities that are so time-consuming that they forget about other needs (entertainment, family time), including rest. This study aims to answer the needs of the community, most of the people in the Village office Tanki which are one of the centers of Jakarta through the role of architecture in creating space for relaxation and relaxation amid various activities undertaken (Third Place). In this research, the method used is conducting studies, observations and distributing questionnaires as initial data collection. Second, discussing, discussing and discussing the needs of the surrounding community to complete boredom and restore amidst a lot of and dense activities. Third, compile a program in accordance with the results of the survey, observe and answer the needs of the community that are tailored to the problem so that the creation of a Third Place that successfully makes the project objectives will be obtained. The third place of the Performing Arts project provides and provides the space needed for the community in the Tank Village by developing and requiring an old program from a Lokasari, into a program of making a mixture of cultural lamas using the present age to attract all ages and genders.
\end{abstract}

Keywords: needs; routine; tangki; third place 


\section{PENDAHULUAN}

Permasalahan sosial ini terjadi di kota Jakarta yang semakin lama menjadi semakin kompleks akibat dari tidak meratanya kesejahteraan yang dirasakan oleh masyarakatnya, khususnya di daerah Kelurahan Tangki, Kecamatan Taman Sari. Dengan ciri khas kawasan yang ada ialah Lokasari dan pusat-pusat perdagangan lainnya di sekitar Taman Sari. Orientasi dalam masyarakat yang terlihat di kawasan ini, Taman Sari (Lokasari) sebagai center kota lama dan sejarah masa lalu yang sangat terkenal sebagai pusat hiburan di Jakarta. Tetapi dengan diubahnya fungsi dahulu yang sebagai tempat hiburan, lalu sekarang menjadi Plaza berisikan toko-toko dan tempat makan yang cenderung modern namun kurang menarik, membuat karakter yang ada dari jaman dulu menjadi berubah seiring berkembangnya zaman dan menjadi kawasan yang berbeda dibanding sejarah dulunya.

Dengan fungsi zaman dulu sebagai panggung pertunjukan berupa theater, opera, galeri musik dan bioskop, menjadikan kawasan ini pada zaman itu menjadi salah satu icon kota Jakarta. Pada saat ini, para pedagang dan masyarakat asli yang tinggal sejak dulu sudah banyak yang pergi dan banyak juga yang masih menetap di kawasan ini karena turunan dari orang tua terdahulu. Pusat hiburan yang dulunya sangat ramai, sekarang menjadi sepi dan bahkan ada yang sudah tidak beroperasi lagi. Jika hal ini terus berlanjut, mungkin saja kawasan Lokasari akan punah dan para pedagang, pekerja, maupun komunitas yang ada akan kehilangan pekerjaan dan tempat berkumpul mereka. Meski ada Plaza Lokasari sebagai hal modern zaman sekarang, tetapi hal ini tidak memberikan dampak yang signifikan terhadap kawasan ini sendiri. Karena itu, Lokasari harus lahir kembali dengan konsep baru atau hidup kembali sebagai The Third Place yang mampu memberikan wadah bagi para masyarakat Tangki dan sekitarnya dan membuat program-program yang berfungsi agar para pengunjung dapat saling bersosialisasi dan berinteraksi dengan sesamanya. Serta menghidupkan kembali beberapa fungsi lama yang menjadi icon kawasan, sehingga bukan hanya masyarakat sekitar Tangki yang bernostalgia, juga para pendatang ikut merasakan suasana Lokasari zaman dulu yang di combine dengan zaman modern teknologi sekarang. Dengan demikian, kualitas hidup penduduk dan pengunjung akan meningkat serta Lokasari memiliki banyak aktivitas-aktivitas baru.

\section{KAJIAN LITERATUR (11pt)}

\section{Third Place}

Menurut Oldenburg (1989) menjelaskan bahwa third place merupakan sebuah lingkungan sosial yang terpisah dari dua lingkungan lainnya, yaitu rumah (first place) dan tempat bekerja (second place). Di mana third place ini merupakan sebuah wadah kehidupan komunitas yang memfasilitasi serta mendorong terjadinya interaksi yang lebih luas dan kreatif. Third place juga merupakan sebuah tempat di mana semua orang dapat datang untuk melakukan berbagaimacam kegiatan mulai dari bersantai hingga berjumpa dengan orang baru.

\section{"Sharing Cities" Duncan McLaren}

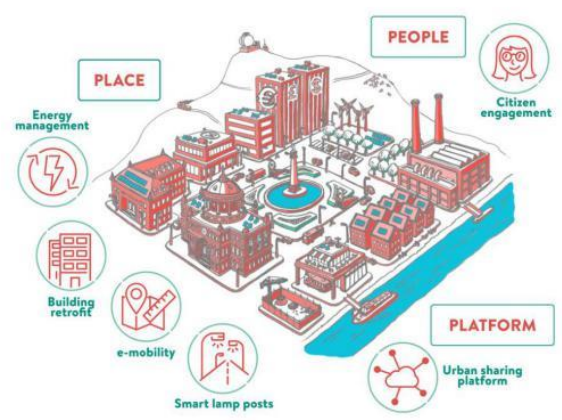

Gambar 1 Sharing design kota yang diharapkan Sumber: Duncan McLaren, Sharing Cities, concept design city 
Kota selalu tentang ruang bersama, interaksi dan pertemuan manusia, dan pertukaran barang dan jasa melalui pasar dan pinjaman uang. Kota yang sukses membutuhkan pemerintahan yang baik dan struktur sipil kolektif untuk memfasilitasi dan mengatur antarmuka antara ranah publik bersama dan kepentingan pribadi, dan untuk memungkinkan pembagian sumber daya dan peluang yang efektif dan adil. Akan tetapi, dalam inkarnasi mereka yang lebih baru, berbagi biasanya dipahami secara sempit dan dianggap terutama tentang transaksi ekonomi, apa yang disebut ekonomi berbagi. Kota pintar berinvestasi dalam teknologi informasi dan komunikasi (TIK) berteknologi tinggi untuk "menyatukan" kota dan meningkatkan efisiensinya, mendorong sektor TIK sebagai motor pertumbuhan dan pengembangan properti, dan menarik bakat terampil dengan memberikan kualitas hidup yang tinggi. Salah satu tujuan dalam buku ini adalah menunjukkan betapa kota yang benar-benar pintar juga harus berbagi kota.

\section{Sharing tentang kota California, San Fransisco}

San Francisco, California, berada di garis depan gelombang konsumsi kolaboratif modern dengan perusahaan berbagi teknologi tinggi, startup berbagi baru, dan pengembangan normanorma baru di kalangan kaum Millenial. Ini adalah rumah bagi perusahaan seperti Twitter (jejaring sosial online dan layanan micro-blogging), Dropbox (perusahaan penyimpanan berbasis cloud), Airbnb (pasar komunitas online untuk pemesanan akomodasi), dan Lyft (aplikasi seluler ridesharing). Dalam beberapa tahun terakhir, pertumbuhan lapangan kerja teknologi tinggi baru di pusat kota San Francisco telah melampaui di pusat-pusat perusahaan lama di daerah pinggiran kota. Pergeseran ini mencerminkan norma yang berubah di antara generasi Millenial $\_$generasi yang menyediakan tenaga kerja dan basis konsumen dari startup ini. Pusat kota San Francisco menarik orang-orang muda yang mengadopsi gaya hidup bersama dan berbagi, menghindari kepemilikan mobil, dan mengurangi konsumsi. Beberapa kriteria dari third place:

a. Openess (keterbukaan)

Inklusif dan kesetaraan merupakan kriteria terpenting, di mana harus dapat menghilangkan kesenjangan antara kaya dan miskin, muda dan tua sehingga semua orang dapat masuk kedalamnya tanpa terkecuali; Sharing space, tidak adanya batasan antara ruang baik itu publik dan private; Permeabilitas, Dapat ditembus oleh siapapun; Tempat pertukaran informasi

b. Flexibility (Flexibilitas)

Memiliki program campuran segingga dapat menghidupkan kota 24 jam; Kebebasan dalam negolah ruang.

c. Contextuality (Kontekstualitas)

Bersifat universal dan konteks; Menjawab kebutuhan manusia di sekitarnya; Adanya hubungan dengan lokalitas setempat, kehidupan sosial-budaya dan sejarah.

\section{METODE}

Dalam proses metode perancangan ini terdapat beberapa metode yang dilakukan perancang untuk mengumpulkan data, yaitu wawancara, survey, dan dokumentasi. Data ini dibagi menjadi dua yaitu data primer dan data sekunder. Data primer adalah data yang didapat secara langsung dari sumber asli atau tidak memiliki perantara, sedangkan data sekunder adalah data yang diperoleh perancang secara tidak langsung yaitu melalui media perantara. Metode yang digunakan adalah metode Explosing yaitu mencari inspirasi dengan berpikir secara kritis untuk menghasilkan suatu desain yang belum pernah diciptakan. 


\section{DISKUSI DAN HASIL}

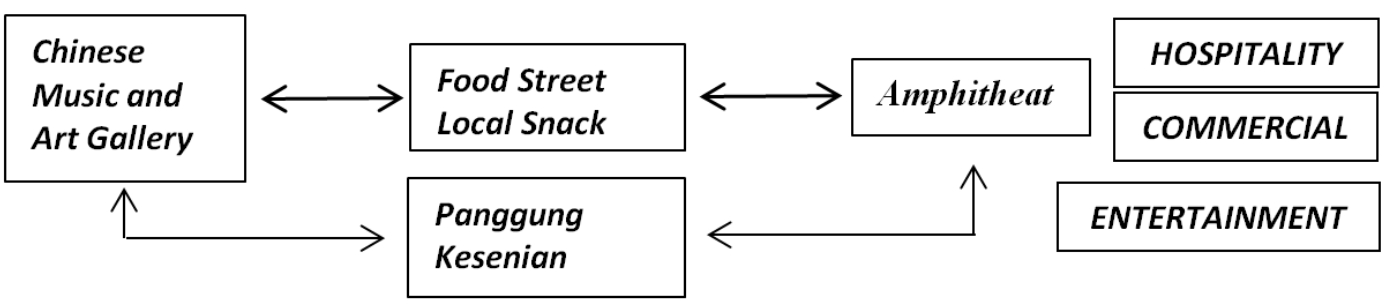

\section{Sejarah Kelurahan Tangki}

Berada di sebuah daerah dekat dengan Batavia tempo dulu, Tangkiwood berasal dari sebuah pemukiman bernama Gang Tangki. Di seberang Gang Tangki inilah dulu berdiri sebuah pusat hiburan di Jakarta yaitu Prinsen Park yang kini disebut dengan kawasan Lokasari. Dapat dikatakan bahwa dari Prinsen Park adalah cikal bakal dari banyak bioskop di zaman modern ini. Bioskop, opera, ataupun teater-teater dari yang lokal hingga berskala internasional hampir setiap malam menghiasi di Tangkiwood. Beberapa artis besar ibukota zaman dahulu bahkan berasal dari Tangkiwood. Tangkiwood tercipta dari kebaikan seorang pemilik Prinsen Park yaitu Tan Hin Hie yang melihat kasihan para wayang orang atau pemain opera yang jika Prinsen Park sudah waktunya tutup, maka mereka selalu tidur di atas panggung. Hingga akhirnya didirikanlah penginapan bagi para pemain teater dan opera di sana.

Wajah Prinsen Park kini menjadi berubah 180 derajat dari yang sebelumnya sebagai pusat hiburan Jakarta dengan berbagai pertunjukan dan taman bermain yang seru, menjadi sebuah kawasan yang dianggap minus. Sejak beberapa dekade terakhir semenjak pusat pertunjukkan menggunakan gedung megah yang kini menjadi Gedung Kesenian Jakarta, Prinsen Park (Lokasari) hampir pudar di masyarakat sebagai pusat hiburan Jakarta. Prinsen Park (Lokasari) yang dulu tak pernah sepi, sekarang menjadi pusat hiburan seperti kuburan. Hampir setiap orang yang dahulunya datang untuk melihat pertunjukkan komedi, opera ataupun teater mulai ke gedung megah ataupun bioskop.

\section{Kondisi Eksisting sekitar Tapak}

Bangunan yang mendominasi berupa hunian, tidak jarang juga banyak dari hunian ini bersatu dengan tempat mereka berjualan dan banyak ruko-ruko dengan fungsi berjualan, kantor, apotek, dll. Kawasan Tangki menjadi salah satu kelurahan di Jakarta Barat yang penuh dengan sejarah yang menarik,dari segi hiburan, kuliner, budaya, dll. Dengan jumlah penduduk 15.221 (BPS 2018) menjadikan kelurahan ini menjadi padat penduduk dan menjadi salah satu pilihan hunian di Kecamatan Taman Sari. Hal yang iconic di kawasan ini ialah Lokasari. Karena kawasan ini lebih dikenal dengan kawasan hiburan malam, terdapat banyak tempat-tempat hiburan seperti cafe, diskotik, mandi uap, billyard, karaoke hingga night club (BPS 2018).

Dengan dominasi kawasan 1st Place dan 2nd Place menjadikan kawasan Tangki menjadi cukup padat dan salah satu tujuan orang-orang dari dalam sampai keluar Tangki. Dominan tempat tinggalnya pun, rata-rata yaitu peranakan dari orang tua mereka ataupun dari kakek atau nenek mereka. Hal ini menjadikan banyaknya turunan orang Tionghoa yang tinggal karena memang menjadi kawasan masyarakat Tionghoa. Beberapa ruko dan toko yang berjualan tidak sedikit yang berjualan bakmi, kwetiau, restoran chinese, bakso dan bubur. Makanan yang dijualpun menjadi makanan identik lokal Tionghoa karena memang mengikuti jumlah peminat pasar yang banyak. Selain itu, banyak juga ojek online yang menumpuk, baik di jalan ataupun yang membeli makanan lokal sekitar Tangki. Di sekitar Lokasari Square juga ada tempat ibadah, seperti gereja GBI Mangga Besar (350 m) dan Vihara Avalokitesvara (400 m). Masih dengan berjalan kaki, dapat mengakses pusat transportasi publik, seperti Stasiun 
Mangga Besar (650 m) dan Halte Transjakarta Olimo (1,1 km).
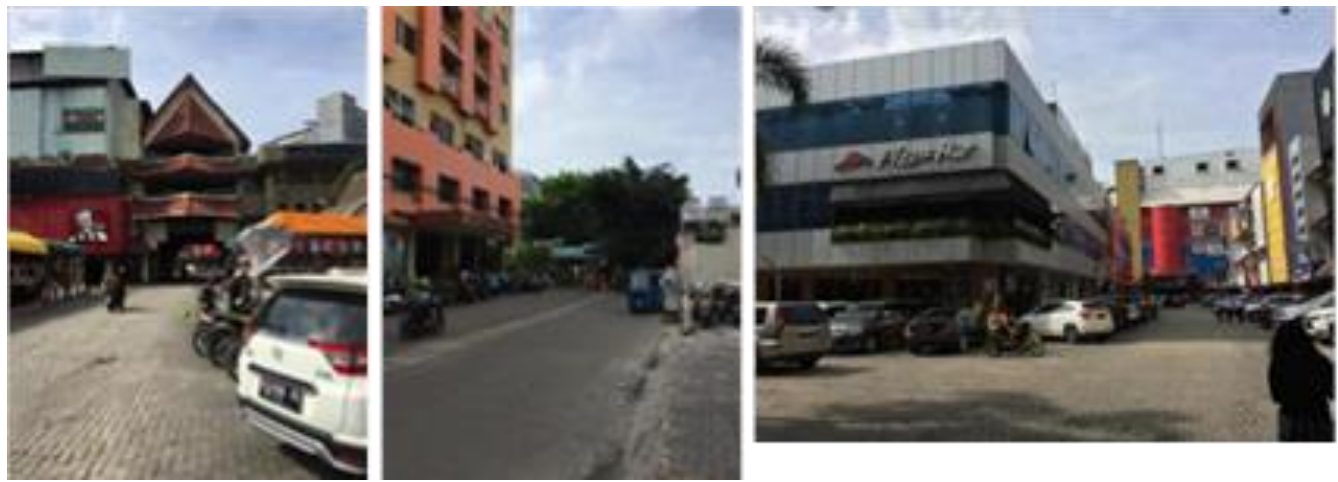

Gambar 2. Area sekitar Site (Lokasari)

Sumber : penulis, 2020

Zonasi Peruntukan : Zona Perkantoran, Perdagangan dan Jasa

Luas Tapak : $6000 \mathrm{~m}^{2}$

Batas Utara : Jl Lokasari Square

KDB : $45=2700 \mathrm{~m}^{2}$

Batas Timur : Ruko Lokasari

$\mathrm{KDH}: 30=1800 \mathrm{~m}^{2}$

Batas Barat : Jl Mangga Besar IX

$\mathrm{KLB}: 2=12.000 \mathrm{~m}^{2}$

Batas Selatan : Jl Load Rot Lokasarl

KB : 4 dan KTB : 55

Pada gambar-gambar tersebut dapat beberapa input bahwa sebenarnya kelurahan Tangki memiliki cukup banyak fasilitas yang dibutuhkan penduduk di kelurahan ini. Tapi sangat disayangkan, bahwa penduduk sekitar mengatakan sangat membutuhkan tempat atau kawasan hiburan. Di saat mereka bisa berkumpul dan menikmati hiburan dengan keluarga dan teman. Masyarakat Tangki merasa sudah kehilangan citra 'Lokasari' yang dulunya sebagai kawasan hiburan di Jakarta yang populer. Ini juga mengakibatkan beberapa pedagang kehilangan pelanggannya karena kawasan ini menjadi sepi dan pembeli yang datang hanya sekedar beli dan pulang.

\section{Analisa User dan Aktivitas}

Kelurahan Tangki sebagai salah satu pusat hunian dan perdagangan di Taman Sari dan memiliki banyak pengguna dengan aktivitasnya yang sangat beragam. Dari data-data tersebut dapat diperoleh seperti :

\section{Aktivitas yang Bertahan dari Pagi Hingga Malam}

Bekerja dan Berdagang: Di jalan Mangga Besar IX dan di dalam kawasan Lokasari merupakan area perdagangan yang bekerja dari pagi hingga malam. Pagi terdapat pasar Tangki yang ramai dan ruko-ruko dengan fungsinya mulai buka juga. Siang masih bertahan beberapa pedagang dan orang-orang yang bekerja di ruko di pinggir jalan Mangga Besar IX, Tangki Lio dan kawasan Lokasari. Lalu malam hari mulai berdatangan orang yang berjualan makanan-makanan lokal (nasi goreng, ayam bakar, pecel ayam,dll). Juga pada malam hari mulai ramai di warung kopi karena disitu menjadi salah satu pusat orang-orang sekitar hunian berkumpul. Dilihat dari beberapa aktivitas yang bertahan dari pagi hingga malam, menurut pengamatan di lapangan memang untuk berkumpulnya orang untuk bersosialisasi tidak ada dan terbatas. Kebanyakan penggunanya juga anak muda dan orang tua rata-rata dirumah masing-masing.

Kuliner : Terpusat di kawasan Lokasari, Mangga Besar IX dan Tangki Lio. Para pedagang di sana kebanyakan mulai berjualan dari pagi hingga malam. Salah satu kuliner favorite ayam tulang lunak dan bakmi Koh Aseng. 


\section{Aktivitas yang Dominan dilakukan di Tangki}

Kebanyakan orang-orang bekerja ke luar Tangki, pedagang kaki lima, kuliner dan pertokoan. Memang rata-rata masyarakat Tangki menjadikan kawasan ini menjadi 1st Place dan 2nd Place, tapi tidak jarang juga beberapa orang diluar Tangki datang untuk makan, kuliner dan beberapa orang duduk-duduk di bawah pohon-pohon. Dari beberapa pertanyaan yang diajukan ke pengguna di kawasan Tangki, minimnya tempat terbuka umum menjadi kendala utama untuk datang ke kawasan Tangki. Mereka harus membeli sesuatu terlebih dahulu untuk dapat duduk-duduk ataupun bersantai. Sampai akhirnya mereka mencari dan membuat 'pangkalan' mereka sendiri hanya untuk sekedar bersantai dan berbincang dengan teman mereka. Juga salah satu rutinitas pengguna di dalamnya, memang hanya untuk mencari kebutuhan mereka dan langsung pulang ke rumah. Padahal, jika ditarik dari sejarah kawasaan Tangki, Lokasari dulunya menjadi tempat berkumpul, berjualan, hiburan dan berinteraksi dengan orang lain.

\section{Kebutuhan tempat hiburan dan sejarah Lokasari masa lalu masih melekat}

Melihat dari kebutuhan masyarakat Tangki, berdasarkan hasil wawancara, kebanyakan dari mereka yaitu memiliki kebudayaan Tionghoa. Dan kebanyakan peranakan dengan budayabudaya Tionghoa. Jadi mayoritas dari mereka mengetahui sejarah dari Lokasari dan tertarik dengan kebudayaan Tionghoa dan icon dahulu di Lokasari. Untuk masyarakat yang ekonominya mampu mereka mengatakan, rata-rata third place atau hiburan mereka yaitu ke mall. Di mana mereka bisa berinteraksi dengan orang lain di mall dan memiliki hiburan yang diinginkan. Tapi, tidak sedikit juga dari mereka, yang ekonomi rendah, tempat hiburan mereka ialah Kota Tua. Dimana orang bisa bersosialisasi, duduk-duduk santai, mencari kuliner sekitar Kota Tua. Karena hanya itulah tempat ruang terbuka yang dirasa cocok, baik dari segi ekonomi, usia, gender, dll. Padahal berdasarkan analisis yang dilakukan, jika fungsi Lokasari masih dijadikan dan masih sama dengan fungsinya seperti dulu, memiliki potensi besar untuk menjadi pusat hiburan di kawasan Tangki

\section{Latar Belakang Pemilihan Kawasan}

Terdapat beberapa kriteria yang merujuk pada pemilihan lokasi kawasan yang spesifik, antara lain; kawasan minim ruang terbuka umum, fasilitas umum dan ruang terbuka hijau (RTH) Kurangnya fasilitas umum berupa taman terbuka hijau yang dibutuhkan berdasarkan hasil survey (analisa user dan aktivitas). Juga hasil pertanyaan yang telah di lempar ke masyarkat, kebanyakan dari mereka menjadikan Kota Tua menjadi salah satu tujuan utama hiburan mereka. Berdasarkan pengalaman pribadi dan pertanyaan ke beberapa anak muda sekitar, mereka butuh tempat yang bertahan hingga larut malam karena pada pagi hingga sore mereka bekerja dan memiliki waktu untuk bersantai dan bertemu dengan teman hanya waktu malam, sedangkan untuk melakukan itu, hanya ada tempat warung roti panggang dan cafe untuk mereka dapat bersantai dan ngobrol hingga larut malam. Dilihat dari aktivitas dan penggunanya, bukan hanya fasilitas umum yang dibutuhkan, namun ruang atau tempat untuk bercengkrama dengan waktu hingga larut malam. Karena banyak orang tua menyediakan tempat duduk di depan rumah mereka untuk dapat berkumpul dan mengobrol dengan teman atau tetangga sekitar. Juga berdasarkan sejarah, kebanyakan dari penduduk masih memiliki adat berkumpul dengan kegiatan masing-masing, seperti bermain catur Cina dan masih ada yang membuat kaligrafi Cina. Kebutuhan ini yang mendasari butuhnya ruang terbuka umum dan butuhnya ruang hijau di kelurahan ini. Ingin memunculkan dan menghidupkan kembali fungsi awal yang sebagai tempat hiburan dan pertunjukkan seni pada zamannya.

\section{Potensi Lokasi dan Permasalahan}

Potensi lokasi Transit Oriented Development (TOD)

MRT Jakarta merancang desain konstruksi kereta yang terintegrasi dengan moda transportasi lain, pedestrian untuk pejalan kaki, dan jalur pesepeda. Jadi fase 2 sembari membangun 
infrastruktur MRT, juga mulai bangun fasilitas-fasilitas yang memudahkan konektivitas atau interkoneksi dengan moda transport yang lain sekaligus membangun TOD. MRT fase 2 dengan rute Bundaran $\mathrm{HI}-K o t a$ akan melintang sepanjang 8,3 kilometer. 7 stasiun baru akan dibangun, yakni Sarinah, Monas, Harmoni, Sawah Besar, Mangga Besar, Glodok, dan Kota.

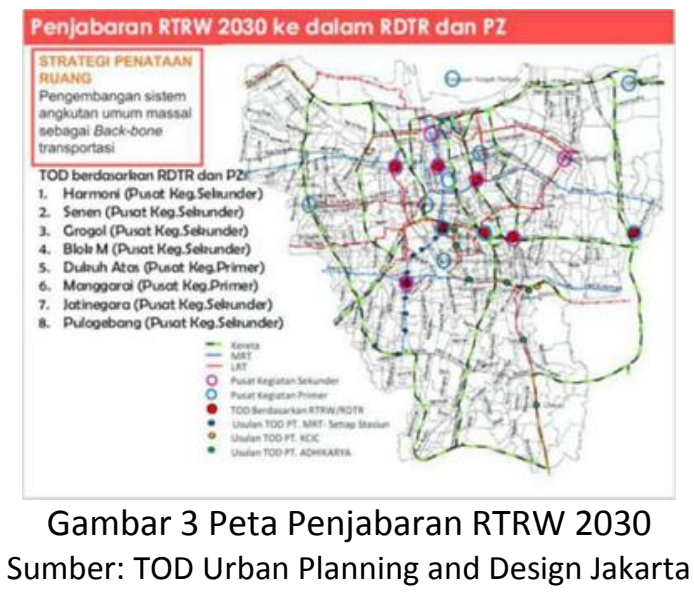

\section{Berpotensi third place ramai pengguna}

Dari hasil survey ke beberapa orang sekitar Tangki mengatakan, daerahnya sangat membosankan, dimana mereka hanya melakukan rutinitas setiap hari dengan bekerja, sekolah dan pulang ke rumah. Masih belum adanya tempat communal yang mampu menampung pengguna di kawasan Tangki. Padahal mereka sangat menginginkan public space namun pilihan tersebut hanya bertuju pada Plaza Lokasari, Grand Paragon dan Gajah Mada Plaza yang mampu menampung hiburan mereka. Sedangkan di beberapa kalangan, untuk menuju ke mall terbatas karena biaya dan mereka yang kurang mampu menuju third place berupa pasar malam dan kawasan Kota Tua. Hal ini dapat berkembang dan memiliki potensi luas dengan menggabungkan fungsi lama dengan berbagai sejarah kawasan Lokasari, dipadukan dengan era zaman sekarang dan penduduk sekitar Tangki.

\section{Permasalahan sekitar kawasan}

Kawasan Tangki memiliki banyak kasus kebakaran di Lokasari dan sekitarnya. Dalam waktu 1 tahun sudah terjadi 3 kali kebakaran di kawasan Lokasari. Meski hal ini sering terjadi, beberapa tempat di Lokasari minim keamanan untuk mengatasi kebakaran. Kemudian, karena kebanyakan penduduk sekitar mengetahui sejarah awal Lokasari sebagai hiburan dan kini menjadi sebuah Plaza Lokasari seperti 'mall'. Dengan perubahan ini, kebanyakan dari mereka kecewa oleh Pemprov DKI karena menghilangkan ciri khas atau icon kawasan. Karena hal ini berdampak ke sekitarnya, berupa tempat berjualan, kawasan menjadi sepi dan rata-rata orang hanya datang dengan keperluannya lalu pergi

\section{Program Kegiatan}

Masyarakat kota terkenal akan kesibukannya tak terkecuali masyarakat di Kelurahan Tangki, dimana aktivitas dan rutinitas utama mereka adalah bekerja. Ketika mereka berangkat bekerja mereka cenderung terburu-buru sehingga mereka membutuhkan sesuatu kegiatan yang bersifat cepat, namun tetap dapat membuat mereka tenang. Sedangkan ketika mereka pulang cenderung membawa stress sehingga mereka membutuhkan sesuatu kegiatan yang bersifat menyenangkan, menenangkan, dan menghibur bagi mereka. Dengan memadukan programprogram Lokasari lama dengan kebutuhan orang-orang sekitar di Kelurahan Tangki, baik usia, gender, pekerjaan. Hasil-hasil program ini diharapkan akan menjadikan daerah Tangki terdapat tempat hiburan yang baik dan netral. 


\begin{tabular}{|c|c|c|c|}
\hline AKTIVITAS \& PROGRAM RUANG & WAKTU & HARIAN MINGGUAN/BULANAN & TAHUNAN \\
\hline PERTUNJUKKAN & SORE - MALAM & & \\
\hline PAMERAN & PAGI - MALAM & & \\
\hline FOOD COURT & PAGI - MALAM & & \\
\hline AREA MULTIFUNGSI & SESUAI KEBUTUHAN & & \\
\hline WORKSHOP & SESUAI KEBUTUHAN & & \\
\hline SANTAI, ISTIRAHAT & PAGI - MALAM & & \\
\hline
\end{tabular}

Gambar 4. Aktivitas Program pada proyek

Sumber: penulis, 2020

\section{Bentuk Rancangan}

Bentuk dasar bangunan berasal dari aksis tapak, orientasi banyak orang yang beraktivitas di sekitar Plaza Lokasari yang kemudian dipisah menjadi dua bagian berdasarkan hasil dari analisa tapak. Selanjutnya massa yang sudah terpisah menjadi dua bagian diangkat keatas berdasarkan pemenuhan program yang ada, serta fokus bukaan banyak berada di sisi sebelah kanan atau dekat dengan jalan Mangga Besar IX. Lalu di sebelah kiri tapak berdekatan dengan ruko-ruko lama yang hampir mati. Ingin membangkitkan aktivitas dan menggapai para pengguna ruko-ruko lama tersebut agar wilayahnya dapat aktif dengan kegiatan yang ada. Penempatan plaza di tengah bangunan bertujuan menjadikan pusat kegiatan dan dapat dilihat dari dalam dan luar bangunan.
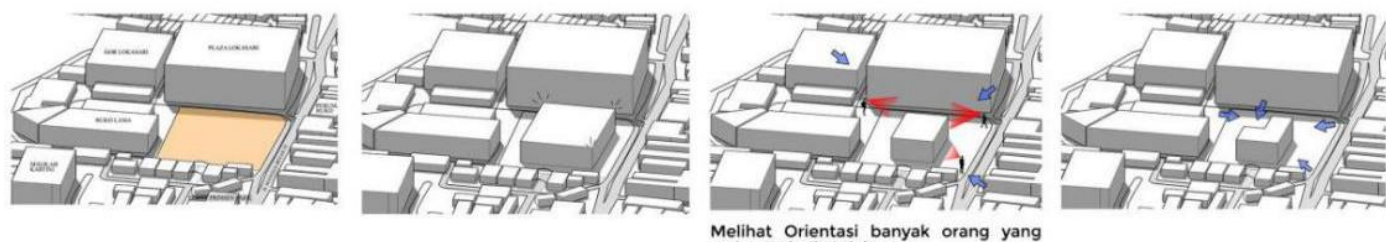
Melinat Orientasi banyak orang yang
sering terjadi aktivitas
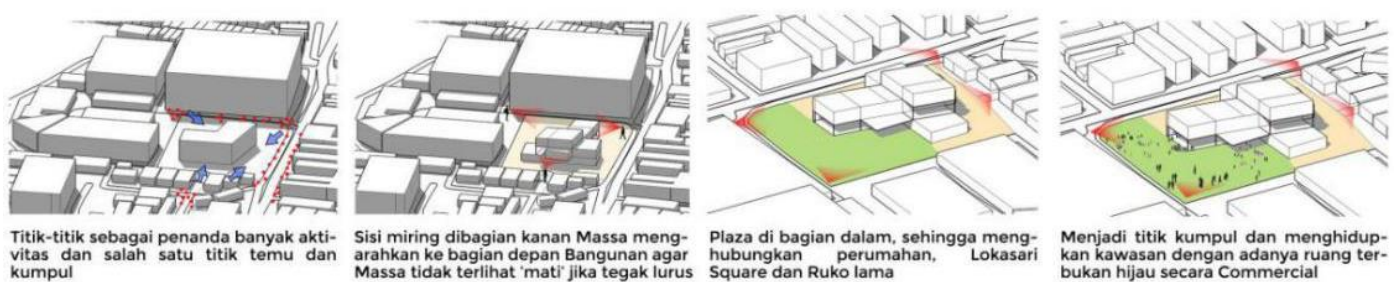

Gambar 5 Pembentukan massa bangunan Menjadi titik kumpul dan menghidupvitas dan salah satu titik temu dan
kumpul Sumber: penulis, 2020

\section{Deskripsi Design}

Seni Pertunjukan di Lokasari merupakan sebuah proyek yang memiliki tujuan untuk menjawab kebutuhan masyarakat, terutama masyarakat Kelurahan Tangki yang merupakan salah satu daerah transisi antara kota Jakarta terutama masyarakat Kelurahan Tangki yang merupakan salah satu daerah pusat kota Jakarta melalui peran arsitektur dalam menciptakan ruang untuk beristirahat dan relaksasi ditengah kepadatan aktivitas yang dijalani (Third Place). Proyek ini memiliki dua titik yang dijadikan dasar dalam perancangan dimana pengunjung dapat datang melalui 3 titik yaitu :

Dari dalam kawasan Lokasari

Pengunjung dari dalam kawasan Lokasari akan terlihat drop off serta area pameran yang berdekatan. Ada juga ruang pengelola yang berada di dekat entrance. Bila menggunakan kendaraan dapat memakirkan kendaraan di sebelah kiri bangunan, lalu dapat langsung masuk ke dalam bangunan melalui tangga dan ramp. 
Dari sebelah Timur bangunan, dekat dengan jalan Mangga Besar IX

Dari arah ini mengarah dari perumahan Tangki yang menghadap ke tapak dan proyek. Di titik dekat Plaza Lokasari menjadi titik orientasi banyak orang, dimana banyak orang berjualan serta aktivitas. Dari arah ini bagi pengunjung yang menggunakan kendaraan, dapat drop off dengan adanya layby, sehingga tidak berhenti sembarangan dan membuat kemacetan dikarenakan jalannya kecil.

\section{Dari arah Plaza Lokasari}

Para pengunjung yang ingin datang hanya bisa berjalan kaki (pedestrian). Pada arah ini memang difokuskan untuk pejalan kaki dan pesepeda sehingga tidak terganggu dengan kendaraan. Banyaknya vegetasi yang berdekatan dengan jalur pedestrian membuat teduhnya saat berjalan mengelilingi taman dekat dengan pedestrian. Lalu di sebelah barat laut, juga terkoneksi menuju proyek dekat dengan food street outdoor (area multifungsi).

Outdoor Plaza dan Live Music Area ini ditempatkan di tengah bangunan yang menjadi titik pusat dan titik temu dari bangunan sehingga pada lantai 2 memiliki balkon dan area split level yang dapat menghadap langsung ke area outdoor hal ini diharapkan agar pengunjung dapat ikut menikmati pertunjukkan yang ada tanpa harus terikat di suatu tempat. Indoor Cinema dan Auditorium ini ditempatkan di lantai 3 dengan akses tangga dan lift. Meski di lantai 3, akses menuju tempat atau area lain tetap terhubung. Jadi meski pengunjung dari area manapun tetap bisa terkoneksi melalui area lainnya. Yang ditampilkan disini yaitu gabungan pertunjukan seni, seperti drama musikal, pertunjukan musik tradisional Cina dan Betawi ataupun musikmusik zaman sekarang. Sehingga menarik dari berbagai kalangan dan gender.

Area Pameran dan Instalasi terbuka berada di lantai dasar. Lalu di lantai 3 memiliki top installation dengan view taman dan sekitar tapak. Area pameran ini selain memamerkan kesenian lukisan, juga dapat memamerkan hasil pembuatan para pengguna yang membuat lukisan di dalam proyek. Jadi, para pengguna ini membuat di lantai 2 dan memamerkannya di lantai dasar, juga bisa di bawa pulang. Jika belum selesai pembuatannya, memiliki ruangan untuk menyimpan barang-barang hasil pembuatan pengguna dan bahan-bahan dasar.

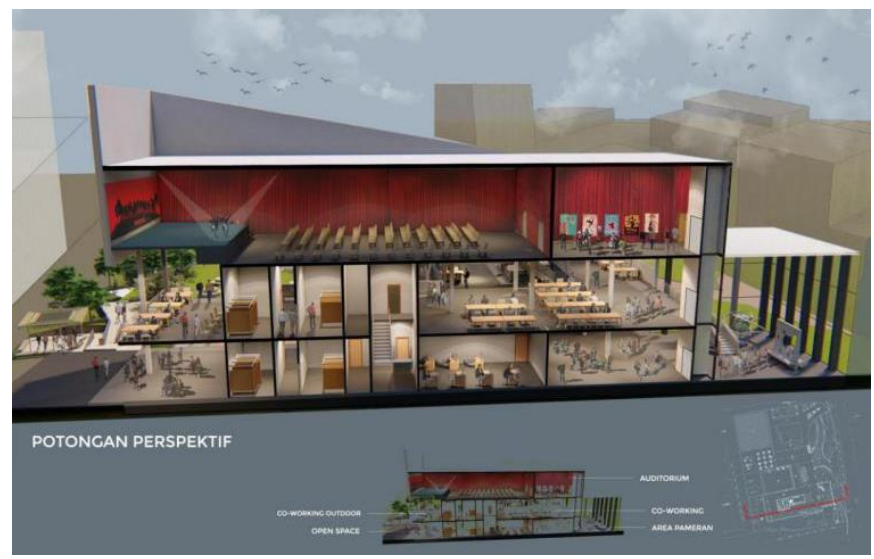

Gambar 6. Potongan Perspektif

Sumber: penulis, 2020

Crafting area ini agar para pengunjung dapat terhibur dengan aktivitas yang baru dan menyenangkan. Mereka dapat meluapkan kesenangan mereka dengan membuat sesuatu dan dapat di pamerkan ataupun dibawa pulang. Pelepasan stress di kala aktivitas yang terus menerus dan cenderung sama, crafting ini diharapkan membuat para penggunanya melepas kejenuhan aktivitas rutin mereka. 


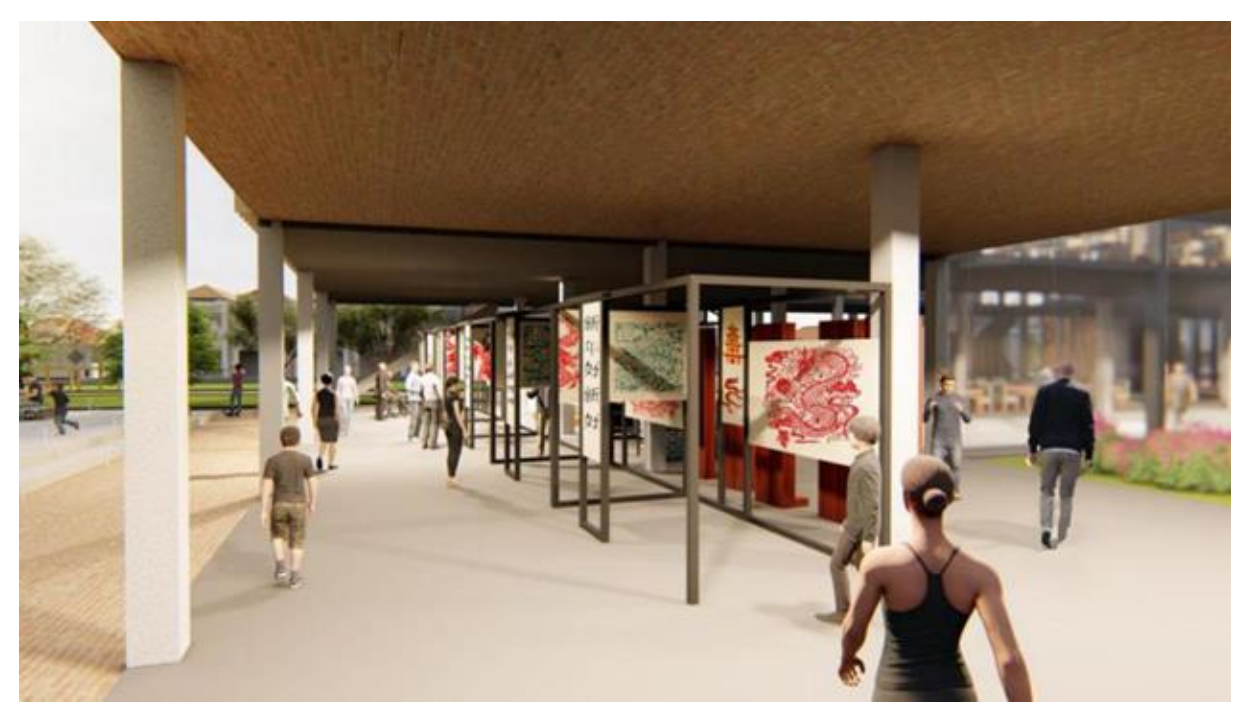

Gambar 7. Area Pameran Indoor

Sumber: penulis, 2020

Co-working space dan retail memiliki area yang berdekatan. Co-working ini memiliki area indoor dan outdoor. Area ini selain tempat berkerja atau mengerjakan tugas, juga sebagai tempat berkumpul dan berbincang. Selain itu, juga bisa melihat view luar bangunan serta plaza yang berada di tengah bangunan. Juga disediakan permainan kebudayaan Cina, sehingga dapat menambah daya tarik pengunjung. Jadi para pengunjung dapat bebas melakukan aktivitas apapun di dalam area bangunan. Retail yang ada ini berjualan makanan khas Cina dan Betawi. Karena sudah jarang menjual di area kelurahan ini, diharapkan proyek ini menjadi wadah bagi mereka.

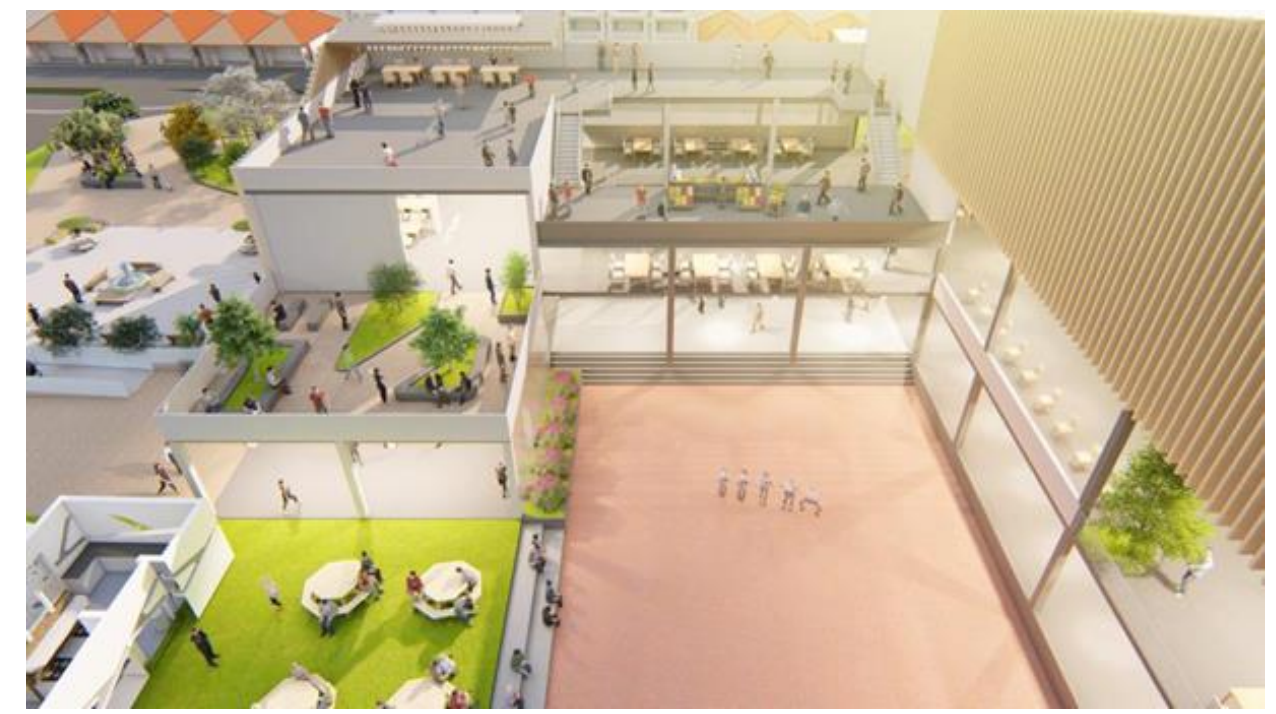

Gambar 8. Perspektif area plaza dan roof garden Sumber: penulis, 2020

Fasad bangunan yang digunakan menggunakan second skin berupa kayu bengkirai. Second skin ini digunakan di bagian depan bangunan sebagai hiasan dan belakang bangunan sebagai penggunaan pencahayaan alami selama pagi-siang hari. Sehingga pada lantai 2 nya dapat sambil melihat pemandangan taman di bagian belakang bangunan. Selain itu pada bangunan banyak menggunakan meterial kaca namun dapat pula dibuka agar tetap mendapatkan udara alami. 
Area ruang luar (taman dan installation outdoor) mengarahkan para pengguna yang berasal dari titik-titik masuk dapat diperkenalkan dengan program-program yang ada pada proyek. Yang dari luar dapat melihat program ataupun kegiatan yang berada di dalam bangunan (lantai 1) dan juga sebaliknya. Adanya area-area duduk yang menjadi tempat untuk bersantai, beristirahat dan ngobrol pada penggunanya. Area luar ini fokus pada akses pejalan kaki dan pesepeda. Dengan kejenuhan aktivitas rutin, area ruang terbuka ini menjadi tempat yang cocok untuk bersantai dan menjadi tempat third place yang menarik bagi semua kalangan masyarakat, terutama pada Kelurahan Tangki.

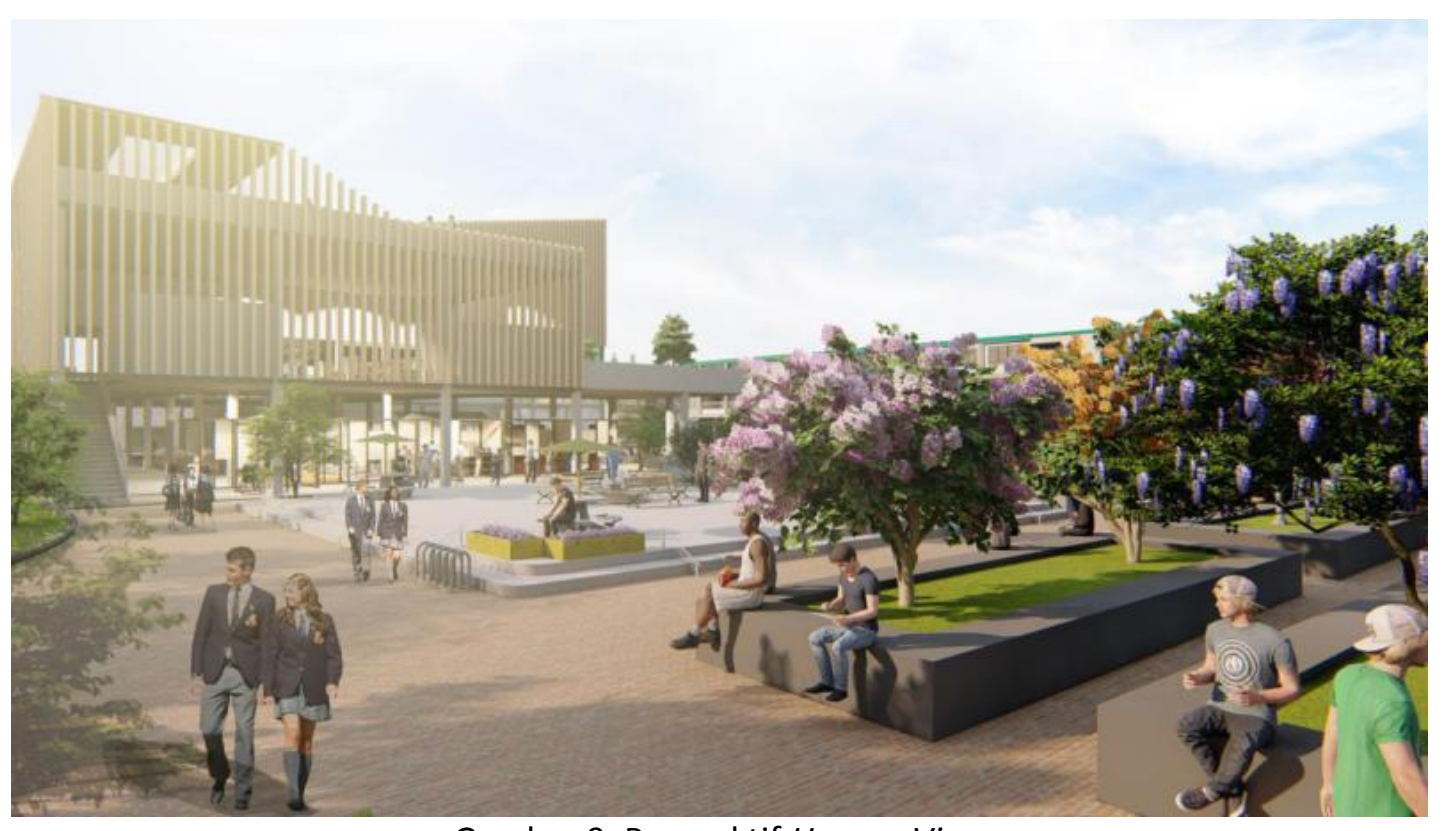

Gambar 9. Perspektif Human View

Sumber: penulis, 2020

\section{KESIMPULAN DAN SARAN}

\section{Kesimpulan}

Proyek third place ini menunjukkan dan memberikan sebuah wadah yang dibutuhkan bagi masyarakat khususnya di Kelurahan Tangki dengan mengembangkan dan membangkitkan program lama dari sebuah Lokasari, menjadi program campuran dari kebudayaan lama dengan kebudayaan zaman sekarang. Yang menjadi visi terbentuknya proyek ini, masyarakat kota dapat memanfaatkan waktu luang mereka dengan beristrahat dan bersenang-senang sambil menikmati pertunjukkan, makanan, berkumpul dan mengobrol sehingga dapat mengatasi kejenuhan dan stress mereka di kala rutinitas harian mereka dan meningkatkan kinerja dalam melakukan berbagai macam aktivitas. Pertunjukan seni khas Cina dan Betawi, Pameran lukisan dan installation, Food court dan Workshop menjadi program utama pada proyek ini.

\section{Saran}

Dalam perancangan proyek third place ini, diperlukan pemahaman yang mendalam terhadap karakteristik khas kawasan. Aspek-aspek vernakular suatu kawasan seperti budaya, iklim, kebiasaan dan juga aktivitas kawasan perlu dipertimbangkan. Hal ini penting untuk mempertahankan kekhasan kawasan dan penunjang kawasan.

\section{REFERENSI}

Bhabha, H. K. (2004). The Location of Culture. Abingdon: Routledge

Duncan, M. Sharing Cities: A Case for Truly Smart and Sustainable Cities. Cambridge: George W Howard, E. (1898). Garden Cities of To-morrow. London: S.Sonnenschein\&Co. 
Januarius, A. (2012). Study Tingkat Kebosanan Dalam Waktu Luang pada Mahasiswa Baru Universitas Kristen Petra Surabaya. Diakses 12 Desember 2019, dari http://digilib.petra.ac.id Montgomerry, C. (2013). Happy City. Canada: Farrar.

Oldenburg, R. (1997). The Great, Good Place. Cambridge: Da Capro Press. 